\title{
The lung cancer patient, the pneumologist and palliative care: a developing alliance
}

\author{
Torsten Blum and Nicolas Schönfeld
}

Number 6 in the series "Challenges and controversies in thoracic oncology" Edited by J-P. Sculier, B. Besse and P. Van Schil

\author{
Affiliation: \\ Klinik für Pneumologie, Lungenklinik Heckeshorn, HELIOS Klinikum Emil von Behring, Berlin, Germany.

\section{Correspondence:} \\ Torsten Blum, Klinik für Pneumologie, Lungenklinik Heckeshorn, HELIOS Klinikum Emil von Behring, \\ Walterhöferstr. 11, 14165 Berlin, Germany. \\ E-mail: torsten-gerriet.blumahelios-kliniken.de
}

ABSTRACT Considerable evidence is now available on the value of palliative care for lung cancer patients in all stages and at all times during the course of the disease. However, pneumologists and their institutions seem to be widely in arrears with the implementation of palliative care concepts and the development of integrated structures.

This review focuses on the available evidence and experience of various frequently unmet needs of lung cancer patients, especially psychological, social, spiritual and cultural ones. A PubMed search for evidence on these aspects of palliative care as well as on barriers to the implementation, on outcome parameters and effectiveness, and on structure and process quality was performed with a special focus on lung cancer patients.

As a consequence, this review particularly draws pneumologists' attention to improving their skills in communication with the patients, their relatives and among themselves, and to establish team structures with more far-reaching competences and continuity than existing multilateral cooperations and conferences can provide. Ideally, any process of structural and procedural improvement should be accompanied by scientific evaluation and measures for quality optimisation.

@ERSpublications

Pneumologists should get more widely involved in palliative care for lung cancer patients http://ow.ly/CutLY

Previous articles in this series: No. 1: Powell HA, Baldwin DR. Multidisciplinary team management in thoracic oncology: more than just a concept? Eur Respir J 2014; 43: 1776-1786. No. 2: Shlomi D, Ben-Avi R, Balmor GR, et al. Screening for lung cancer: time for large-scale screening by chest computed tomography. Eur Respir J 2014; 44: 217-238. No. 3: De Ruysscher D, Nakagawa K, Asamura H. Surgical and nonsurgical approaches to small-size nonsmall cell lung cancer. Eur Respir J 2014; 44: 483-494. No. 4: Van Schil PE, Opitz I, Weder W, et al. Multimodal management of malignant pleural mesothelioma: where are we today? Eur Respir J 2014; 44: 754-764. No. 5: Kim L, Tsao MS. Tumour tissue sampling for lung cancer management in the era of personalised therapy: what is good enough for molecular testing? Eur Respir J 2014; 44: 1011-1022.

Received: April 172014 | Accepted after revision: Sept 292014 | First published online: Oct 302014

Conflict of interest: None declared.

Copyright OERS 2015 


\section{Introduction}

Recently, in the European Respiratory Review, Sculier [1] listed as a major goal for better care of lung cancer patients the need to give more attention to delivering the diagnosis to the patient and to the introduction of palliative care. Upon searching in the European Respiratory Journal (ERJ), it seems that this goal was well chosen, and the current review will be the first ERJ article fully dedicated to the implementation of palliative care in the area of care for lung cancer patients. Considerable evidence of the importance of palliative care for lung cancer has been published in other journals. Are pneumologists and their institutions well enough prepared and directed towards the complex needs of the numerous lung cancer patients?

The current authors previously briefly addressed this question of the integration of pneumological competence and the requirements of an evidence-based, complex concept of care for lung cancer patients, in another European Respiratory Society (ERS) publication [2]. The main focus of the present article is to deepen and stimulate this development in a more scientific manner. Therefore, we reviewed the structural, medical, complementary and personal aspects of comprehensive care that are important, or perhaps vital, for patients in all phases of their life with the diagnosis of lung cancer, starting from the first professional contact. The key discipline in this first contact for most patients, at least in many countries, is pneumology, underlining the responsibility for pneumologists in designing and guiding individual and general concepts of care. This is a distinct situation compared with patients with other malignancies, who are primarily or majorly treated by oncologists [3].

Besides describing principles and dimensions, as well as the underlying evidence for joint palliative and pneumological care in lung cancer beyond pharmacological, interventional and communicative methods, this review would like to draw attention to a structural development desired for the near future.

\section{Methods}

For this narrative literature review, a thorough PubMed search for evidence on various aspects of palliative care (physical, psychological, social, spiritual and cultural care; goals of and barriers to palliative care; outcome parameters and effectiveness; structure and process quality) was performed with a special focus on lung cancer. This approach excluded non-English literature in PubMed, searches in other medical databases and documents produced by governmental and other influential bodies on the international and national level, in order that the evidence basis of this review might be narrowed. A more comprehensive search for existing evidence as well as a systematic review was beyond the scope of this article.

\section{Goals to achieve}

Historically, palliative care has its origin in the hospice movement, but was decisively influenced and further developed by Dame Cicely Saunders (1918-2005), whose pioneer work with the foundation of the first modern hospice in 1967 has inspired all subsequent concepts of palliative care since then [4]. The generally accepted World Health Organization (WHO) definition characterises palliative care as "an approach that improves the quality of life of patients and their families facing the problems associated with life-threatening illness, through the prevention and relief of suffering by means of early identification and impeccable assessment and treatment of pain and other problems, physical, psychosocial and spiritual" [5]. Nowadays, palliative care has outgrown its roots and constitutes a well-established concept of care. It has spread outside the hospice setting, meaning that it is no longer restricted to the terminal phase of cancerous disease but is also beneficially applied in chronic, nonmalignant illnesses at earlier stages. Yoong et al. [6] summarised recently that palliative care seeks to achieve a better quality of life and mood, an improved symptom control and patient satisfaction, and possibly even a better survival. Furthermore, palliative care is able to improve caregivers' satisfaction and can provide a better use of healthcare resources.

Patients suffering from lung cancer show a high burden of comorbidities and symptoms [7-13], as well as unmet needs, specifically psychological and daily living problems; this was recently systematically reviewed by MAGuire et al. [14]. Lung cancer patients experience more psychological distress in addition to physical hardship than patients with other tumour sites [6, 8, 15-19]. With a wide lack of specific information about lung cancer patients, data from cancer patients in general are helpful for an overview. It was found and is plausible that the prevalence of unmet needs is highly variable at all time-points of the cancer illness [20]. Unmet needs appear to be highest during the treatment, particularly after diagnosis, and post-treatment phase, and decline over time [21]. The most frequently reported needs were those in the activities of daily living and in psychological, information, psychosocial and physical domains, followed by needs within the spiritual domain, communication and sexuality. Particularly in the social domain, lacking education in financial or legal issues or community resources can cause feelings of helplessness and contribute to confusion and poor decision making [22]. 
Suffice it to say that the integration of palliative care concepts in lung cancer care should be mandatory, solely because of the considerable problem of unmet needs, and this was and is true even without the evidence of a significant positive prognostic impact of early palliative care in lung cancer patients. However, this supportive evidence is not lacking. The widely recognised randomised controlled trial by Temel et al. [23] investigated the benefit of a 12-week palliative care intervention supplementary to standard oncological care in comparison to standard oncological care alone in patients with metastatic nonsmall cell lung cancer (NSCLC). Not only were an improvement of quality of life as well as a reduction of depressive symptoms shown, a surprisingly prolonged median overall survival (11.6 months versus 8.9 months; $\mathrm{p}=0.02$ ) was also found, despite a less aggressive therapy at the end of life in the group of patients who received additional palliative care [23]. This discovery of a significant prognostic impact of early and prospectively planned palliative care for lung cancer patients has made oncologists and pneumologists listen seriously. Their monopoly of cytoreductive measures to prolong the life of patients with incurable disease is shaken, at least temporarily, by those who do not only mention quality of life but put this item at the centre of attention.

\section{An integrated multidimensional concept}

One of the basic principles of palliative care is the comprehension of the multidimensional nature of symptoms, with each dimension contributing in differing extent and complexity to the suffering in individual patients. This pioneering perception traces back to Cicely Saunders, who established the "total pain" concept. In her understanding, pain contains four indivisible causative axes: a physical, a psychological, a social and a spiritual dimension. Each of these needs to be adequately assessed and treated in order to provide full relief of pain [24, 25]. Eventually, this holistic approach may be applied in the same manner to all other symptoms, to truly address the afflicted patient as a whole person. Beyond this, the recent palliative care concept provided by the National Consensus Project for Quality Palliative Care (USA) extended the original four-dimensional model to eight domains of care (presented in table 1), which integrate the fundamental principles of a patient- and family-centred palliative care into a multiprofessional environment and continuity among different healthcare settings [26].

\section{Physical dimension}

Numerous international and national guidelines as well as review articles have already extensively covered the somatic component of symptom loads in lung cancer patients, be they directly tumour or therapy related, paraneoplastic in nature, or caused by (most often smoking-related) comorbidities [27-29]. Hence, this review will confine itself to a comprehensive listing of the relevant physical symptoms and their qualifying guidance for therapeutic interventions in a brief tabular form (table 2).

\section{Psychological dimension}

Among different cancer entities, lung cancer patients apparently have the highest frequency of psychological distress [55-57]. Besides the well-described five stages of grief (denial, anger, bargaining, depression and acceptance) of KÜBLER-Ross [58], which are commonly perceived in cancer patients from the very beginning of the disease, the following psychological symptoms and psychiatric disorders were attributed to patients in lung cancer-focused studies or systematic reviews [10, 14, 59-66]: depression, anxiety, adjustment disorder, loss of libido, insomnia, suicidal thoughts, delirium, and nicotine and alcohol dependence. Psychological distress was described for all phases along the lung cancer trajectory, even in the favourable cases of survivors [67], but mental health was reported to deteriorate with progression of disease or impairment $[68,69]$. However, establishing a timely diagnosis of depression in cancer patients still appears to be difficult in practice. According to the review by Levav [70], the resulting "treatment gap" might be equally evoked by doctors or patients as well as their social or healthcare

\section{TABLE 1 Eight domains of palliative care according to the National Consensus Project for Quality Palliative Care (USA) [26]}

$\begin{array}{ll}\mathbf{1} & \text { Structure and processes of care } \\ \mathbf{2} & \text { Physical aspects of care } \\ \mathbf{3} & \text { Psychological and psychiatric aspects of care } \\ \mathbf{4} & \text { Social aspects of care } \\ \mathbf{5} & \text { Spiritual, religious and existential aspects of care } \\ \mathbf{6} & \text { Cultural aspects of care } \\ \mathbf{7} & \text { Care of the patient at the end of life } \\ \mathbf{8} & \text { Ethical and legal aspects of care }\end{array}$


TABLE 2 Physical symptoms in lung cancer and their qualifying guidance for therapeutic interventions

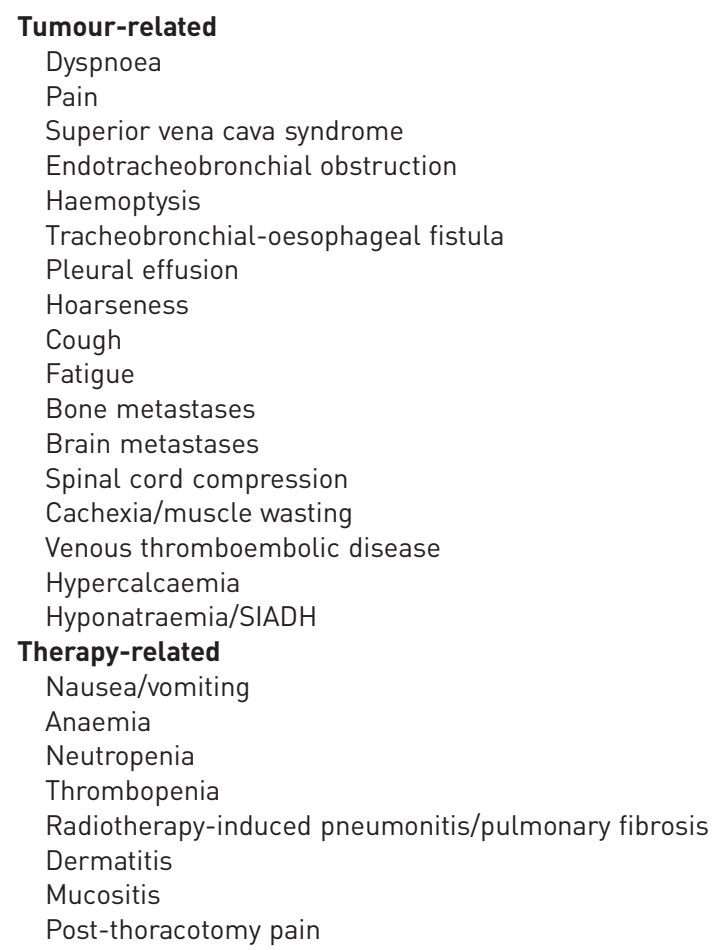

$[27,29,30]$

$[27,28,31]$

[27-29]

[27-29]

[27-29]

$[27,28]$

[27-29]

[29]

$[27,29,30,32]$

$[27,30]$

$[27,29,33,34]$

$[27,29]$

$[27,29,35]$

$[27,28,30]$

[27, 36-39]

$[28,29]$

$[28,40,41]$

$[28,42,43]$

$[28,44,45]$

[28, 46-49]

$[28,51]$

$[28,51]$

[28, 51-53]

[54]

SIADH: syndrome of inappropriate antidiuretic hormone secretion.

network. SHIMizu et al. [71] were able to conclude, from their data from 1334 consecutive lung cancer patients (depression rate 12.4\%), multifactorial patient-related contributors to the severity of depression, among which personal traits as well as coping style seemed to be the most relevant. Conversely, the work of CATALDO and BRODSKY [72] described a perceived lung cancer stigma by patients as an individual negative predictor for depression, anxiety and symptom severity. These circumstances strongly suggest a proactive outreach to lung cancer patients, especially at the time of diagnosis and during treatment.

Encouraging data have been published from cancer patients in general showing that adequate interventions are able to reduce the needs and subsequent depression $[73,74]$. However, a systematic Cochrane review by RUEDA et al. [75] assessing the impact of noninvasive interventions on quality of life and psychological functioning specifically in lung cancer patients was only able to detect 15 smaller, heterogeneous trials. At least some positive evidence for nursing and psychotherapeutic interventions could be derived from these limited data. WALKER et al. [76] investigated evidence on treatment of depression in lung cancer patients. While their systematic review could not demonstrate an effect of specific measures (i.e. antidepressant medication or cognitive behavioural therapies), the authors detected some evidence showing a reduction of depressive symptoms by general improvement in the care of patients with lung cancer, which was later substantiated by the already cited randomised controlled trial of Temel et al. [23]. Additionally, in their recent single-centre study, DelibEgovic and SinANovic [77] described a significant improvement of patient-reported depression and anxiety levels for 40 lung cancer patients in a short-term inpatient palliative care setting compared with 40 controls.

The prognostic relevance of psychological distress in lung cancer has not yet been conclusively clarified. While in the study by AKECHI et al. [78] in 122 consecutive advanced NSCLC patients no significant correlations between psychological distress variables and survival were seen, ARRIETA et al. [79] proved in a prospective design that depression is a negative predictor of treatment adherence (in 82 NSCLC stage IIIB/IV patients; $\mathrm{p}=0.004$ ). In the study by ARRIETA et al. [79], depression was also correlated with poorer survival, which was in concordance with two other trials [80, 81]. Conversely, an active coping style seemed to positively influence survival in a study with 103 lung cancer patients [82]. 
Professional assessment and interventions should also focus on caregivers in order to give relief to their psychological distress, which is evident during the entire lung cancer continuum [83-85].

\section{Social dimension}

Undoubtedly, lung cancer imposes severe existential threats to patients and their families, often unexpectedly disrupting a habitual social structure. Besides the fundamental question of how (long) one will live with a most often deadly disease, social sequelae constitute a critical factor to the overall burden. KIM et al. [86] provided evidence that this is even true for survivors of lung cancer. In their study, lung cancer survivors $(n=830)$ had a significant decline in employment rate from $68.6 \%$ at the time of diagnosis to $38.8 \%$ after therapy, compared with $63.5 \%$ in the control group $(n=1000)$. The qualitative study by CHAPple et al. [87] highlighted various barriers for lung cancer patients in obtaining social welfare benefits. Mosher et al. [88] exemplified the impact of lung cancer on caregivers $(n=83)$, of whom $74 \%$ experienced at least one negative social or economic alteration within the 3 -month observational period. Based on these findings and several other studies [14, 61, 89-95], social implications of lung cancer impose an imminent danger for the vulnerable social environment and well-being of patients and their caregivers.

Generally, outpatient and inpatient social services in palliative care should provide: 1) sociolegal counselling, concerning reorganisation of occupational matters, securing of financial integrity as well as care and supply needs, application for social security benefits whilst taking into account obligatory co-payments, enforcement of rights, and information on further specialised counselling resources; and 2) psychosocial counselling, addressing emotional needs and support, lung cancer stigma, coping strategies, understanding of new/altered roles and relationships, and importance of social networks. Both modalities of professional social service work are closely related and markedly interact.

Notably for pneumologists, patients with terminal nonmalignant respiratory disease do express psychosocial and physical distress in a similar frequency to terminal lung cancer patients [96]. These facts suggest that a specific low-threshold structure is needed for both patient groups in our institutions. Without giving priority to these items and without having established a professional multidisciplinary team, even hospitals focused on the treatment of lung cancer are highly at risk of underestimating, missing or even disregarding the psychosocial needs of the majority of their patients [97, 98]. Maintaining independency and integrity of patients and caregivers should be important goals in comprehensive lung cancer care. At least some evidence exists pointing to successful implementation of effective social service elements in order to achieve these targets $[99,100]$.

\section{Spiritual dimension}

It is disappointing to note that, for present physician communication, one of the lowest rates was reported for discussion of spiritual concerns [101]. However, to exclude the spiritual dimension means to fail to acknowledge the totality of human existence. Understandable reasons for the avoidance of this domain may be lack of time, poor understanding of or lacking education in spiritual matters, feelings of personal vulnerability, and the fact that solutions in the usual sense are difficult. Yet lung cancer patients do have strong spiritual needs, particularly at the first recognition of imminence of dying and then just before dying [102]. Infrequently evaluated especially in lung cancer patients, there is good evidence that spirituality is in general an important component for quality of life and well-being of cancer patients: it plays a major role in coping with cancer, adjusting to life after a cancer diagnosis and treatment, and physical functioning $[103,104]$. Unlike a psychological aspect of behaviour, spirituality is a reality focused on the ultimate meaning of life and death. Thus, the search for explanation for the occurrence of a cancerous disease may evoke spiritual thoughts already at the time of diagnosis. Simple questions like "Why me?" or "What happens to me afterwards?" exhibit existential thoughts with a merely spiritual dimension. It has been shown that a strong faith may contribute to the patient's resilience during treatment, and a preliminary study even indicated that spiritual faith may positively influence the efficacy of chemotherapy and the clinical course of neoplastic disease in lung cancer patients [105].

Caretakers who face questions, remarks or concrete needs expressed by a patient or a relative might involuntarily feel challenged in their own belief. Patients' religious considerations, especially fears, as a consequence of a sudden diagnosis of life-threatening disease or stepwise fading of hope for cure, nevertheless are frequently spoken out or at least indicated between the lines in talks between patients and physicians on major topics of diagnosis and medical treatment. Yet how can physicians in particular become able to catch the ball, or be willing to, in view of the frequently limited perspective and hope for good that medical treatment is able to provide?

Spirituality is a very common need if it is regarded as a broad phenomenon, encompassing all needs, attitudes, values, convictions and practices that transcend our material and objective world, especially as far as the meaning of life and hope are concerned. This topic was addressed in a remarkable statement by 
the National Institute for Clinical Excellence (UK) [106], building bridges and creating openness even for nonbelieving professionals. For patients and professionals, it has to be taken into account that the crisis of religious institutions in Europe has led to the widespread phenomenon of "believing without belonging" [107]. Yet it has been shown that even a short but structured clinical assessment of cancer patients' spirituality is well received by both patients and physicians, and this addresses the domain and enables both sides to plan referrals to hospital chaplains. Such an open communication may even strengthen the patient-physician relationship by trust [108].

\section{Cultural dimension}

Culture distinguishes not only societies but also human individuals, and originates from multifaceted experiences. Besides national, religious, racial or ethnic backgrounds, other factors like age, sex, sexual orientation, language, socioeconomic or educational levels constitute individual cultural virtues. Accordingly, the National Consensus Project for Quality Palliative Care (USA) demanded in its guidelines that "the palliative care program serves each patient, family, and community in a culturally and linguistically appropriate manner" [26].

Williams et al. [109] reviewed the complex interactions of socioeconomic status, sex, ethnicity and race in lung cancer. Beliefs about care differed in a study with 335 lung cancer patients in relation to their ethnic backgrounds [110], as did symptom burden in another study involving 980 patients with pulmonary carcinoma [111]. In a recent study, MARTIN et al. [112] highlighted significant differences in terms of various therapeutic aspects across ethnic groups in 5044 patients with lung or colorectal carcinoma. Previously, the same group reported on distinct variation of objective burden and available resources in 1249 caregivers of a cohort of lung or colorectal carcinoma patients depending on their racial background [113]. TRAEGER et al. [114] investigated race by sex differences regarding depression rates and the use of multiprofessional services in 1043 lung cancer patients and were able to detect substantial distinctions for both study aims. The systematic review by HARDING et al. [115] on preferences in lesbian, gay, bisexual and transgender populations towards palliative care detected only scarce evidence, mostly hinting at the need for further education of professionals. REYGAN and D'ALTON [116] presented a successful educational programme for 201 palliative and oncological care staff members, targeting the needs of sexual minorities. However, much more evidence is needed regarding the provision of convenient multicultural services in palliative care.

\section{Essential skills}

Like all other medical disciplines, good palliative care relies on certain skills. Communication and setting realistic goals together with the patients are thought to belong to the most important competences and will be discussed in this section. Other skills (care of families, other informal caregivers and professionals, and end-of-life care including the bereavement period) have already been reviewed in an excellent manner elsewhere $[117,118]$.

\section{Communication}

Strong and frequent pressure is related particularly to two communicative aspects: on the one hand, patients have to deal with concerns about their family's fears and worries; on the other hand, a sufficient and substantial medical communication is a crucial need of the patients themselves. We can assume that in a majority of patients communicative requirements are not met in a satisfactory manner without palliative care. Besides a knowledge gap and differing parlance, which are commonly perceived as barriers in lay-professional relationships, the communication between lung cancer patients and doctors is further complicated by variable areas of tension in a bidirectional manner: 1) between the capability to break bad news and the readiness to receive and recognise their full impact; or 2) between the capability to express own desires concerning offered treatment concepts and the willingness to accept contrary conceptions.

From the patient's perspective, receiving the diagnosis of lung cancer and its prognostic impact is one of the most emotionally burdensome moments during the disease. Thus, doctors should be aware of diverse, sometimes unpredictable reactions by patients [119]. Tools like the SPIKES protocol provide an advisable communicative structure for professionals when breaking bad news to patients [120].

Recently, Iyer et al. [121] observed in their nationwide study (in the USA) in 450 patients with advanced NSCLC a limited concordance of symptom perception between patients and their oncologists depending on the inquired items (best concordance for haemoptysis, poorest for lack of appetite). Similarly, relevant disagreements with respect to treatment decisions between oncologists and patients or their families were detected in the study of Siminoff et al. [122]. Depression and anxiety, frequently present in lung cancer patients, tend to become chronic and more severe if not addressed early and professionally [76].

It is remarkable that no specific antidepressant treatment has been evaluated so far in prospective studies on these patients, but palliative care in general, with its emphasis on communication, is able to reduce 
psychological symptom load significantly [23, 77]. The need for early empathetic and comprehensive information becomes even more urgent due to the fact that chronic depression is not restricted to patients without the option of cure: even after curative surgery perioperative depression frequently persists [123]. Thus, a comprehensive skilled communication on various aspects of the disease probably offers a preventive effect on patients' attitude to disease, life and future under changing conditions, with a considerable effect on their quality of life. It also helps to save the mental and physical integrity of all professional individuals involved in this process. A purposeful and effective training should thus be offered, especially to all physicians in our institutions where patients first learn about their diagnosis $[124,125]$

\section{Setting realistic therapeutic goals}

According to the World Medical Association International Code of Medical Ethics, it belongs to the duties of physicians towards patients to "always bear in mind the obligation to respect human life" as well as to "act in the patient's best interest when providing medical care" [126]. In the face of a disease as deadly as lung cancer, these commitments must be translated into open and unbiased communication between doctors and their patients.

To meet these ethical demands, doctors often find themselves in the situation of needing to display sophistication in communication skills while at the same time developing patient-oriented, multidimensional and guideline-compliant care plans. Although nowadays some guidance on how to manage this endeavour exists [127], the omnipotent doctor simply does not exist. As an alternative model, good (palliative) care incorporates well-coordinated multiprofessional team play, through which the patient is comprehensively assessed in all aspects of his needs and thereafter more adequately addressed. Moreover, varying communication channels might be used by team members of different professions to assess the real personal desires and needs of a lung cancer patient as well as to guarantee that core messages transmitted from the care team to the patient are well understood and vice versa. This kind of setting would not only professionalise communication in the context of cancer, but allow better personally tailored therapeutic concepts.

However, therapeutic goals should be not only patient-centred, but above all realistic. For patients, reaching factual decisions on the best therapeutic options could be severely impaired while facing and living with a presumably expedited deadly outcome. TEMEL et al. [128] demonstrated in a sequel analysis of their study population of 151 newly diagnosed metastatic NSCLC patients that initial appraisal by patients regarding their own prognosis often appeared inaccurate, whereas this perception in patients could be positively influenced over the course of an early palliative care intervention. However, physicians are equally dependent on a realistic view of lung cancer patients' prognoses in order to prevent over- or under-treatment. Again, a multiprofessional assessment followed by an equitable, collegial decision-making process among the professional team may help to recommend better therapeutic goals to patients even if the ideal strategy naturally remains hard to predict. Within the continuing process of mutual care planning between professionals and patients, advanced care planning is a pivotal step that needs to be addressed by the palliative care team from the very beginning. Notwithstanding, lung cancer care comprises a broad spectrum of therapeutic options ranging from intensive care unit treatment [129] to a "comfort measure only" decision [117], of which none should be excluded in lung cancer patients by default.

Although during the issue of advanced care planning documents that list lung cancer patients' treatment preferences in view of this devastating disease, a high level of psychological distress usually occurs among all involved parties, subsequent clarity may enhance the ability to accept the fate of lung cancer as well as reduce the extent of anxiety and depression, as shown in the study by Hrodo et al. [130].

\section{Barriers for integration of palliative care into routine lung cancer care}

A recent ERS Task Force that provided a first systematic pan-European snapshot on lung cancer care revealed substantial variation across Europe regarding different aspects of palliative care on the local as well as the national level (i.e. guidance for and provision of palliative care in lung cancer) [131]. Thus, the crucial question for the understanding and planning of present and future integrated care is why the highly appealing, holistic concept of palliative care, which has the inherent potential to improve quality of life as well as the process of coping with disease, is not yet available to the majority of lung cancer patients. The answer is complex and naturally depends on the particular setting. However, four factors might explain the present issue.

First, availability of palliative care is clearly dependent on national healthcare expenditure, since multiprofessional settings as well as network structures across the entire lung cancer continuum need not only personal commitment but also proper funding and resources. The recent update of the European Association for Palliative Care (EAPC) Atlas of Palliative Care in Europe provides a broad overview on national organisation of palliative care in Europe (in 46 out of the 53 countries in the WHO European 
region) and reveals substantial variation in types of palliative care services and their availability among European nations [132].

Secondly, access to palliative care seems to be limited, not only due to information gaps, temporal restrictions or geographical residence, but potentially also due to socioeconomic or ethnic background of patients $[114,133,134]$.

Thirdly, awareness and acceptance of palliative care as an emancipated, helpful discipline in lung cancer beyond end-of-life care may be lacking in patients, caregivers and professionals [135-137]. WARD et al. [138] entitled their survey study "Collaborating or co-existing", highlighting appreciation and barriers in medical oncologists towards palliative care services. Equally, AвRAHм [139] concluded that the professionals themselves, and not only their environment, are part of the problem. Certainly, positive attitudes are needed on both sides in order to overcome the prejudice that a curative or at least tumour-controlling strategy on the one hand, and a palliative non-harming strategy on the other hand, exclude each other in lung cancer care.

Fourthly, proof of concept for palliative care is missing for the most part, even in light of the work by Temel et al. [23] and other pioneering studies. In addition to the generally poor prognosis, the majority of lung cancer patients undergoes a progressive deterioration in terms of symptom burden or well-being during the course of their disease, as depicted most recently by KoczYwAS and co-workers [140, 141] in their observational studies involving NSCLC stage I-III $(n=103)$ as well as NSCLC stage IV patients $(n=114)$ over a period of up to 1 year. Thus, outcome analyses for lung cancer patients have already been extended far beyond sole survival or relapse data acquisition [142-148]. Nonetheless, due to its complexity, thriving research of palliative care scientific questions cannot be based on classical clinical trial designs alone but needs an enhanced methodological repertoire, such as quality of care and quality improvement research approaches [149-154].

\section{Structure, processes and time of integration}

Generally, lung cancer care has undergone an evolving process throughout the last two decades, which was marked by the British Thoracic Society recommendations on organisational issues in 1998 [155] and the provisional statement in 2012 of the American Society of Clinical Oncology (ASCO) on early implementation of palliative care [156]. A broad movement of the last decade has been the establishments of multidisciplinary teams; this development was more or less guided by common sense, as the multidisciplinary team concept was extensively propagated at a time when evidence on the efficiency of this structural innovation was still lacking. Even today, as summarised most recently by PoweLL and BALDWIN [157] in the ERJ, the advantages and disadvantages of multidisciplinary teams are still a matter of debate, although their existence is considered to be undeniable. Yet does the establishment of multidisciplinary teams that are determined to make decisions influence the concrete action of caretaking in the same way as multidisciplinary teams are composed: in a multidisciplinary and comprehensive manner? The contrary is probably widely true: multidisciplinary teams or, as they are quite often called, "tumour conferences", are mostly busy with directing the patient either to the surgeon, the oncologist or oncological pneumologist, the radiotherapist or to a palliative care team. Thus, one may even raise suspicion that multidisciplinary teams contribute to a separation of care. However, it seems to be a vast phenomenon that the establishment of multidisciplinary conference teams is not automatically translated into permanent multidisciplinary treatment teams. For example, inadequate multidisciplinary team collaboration may become manifest when observing active tumour-specific treatment during the end-of-life period. Several retrospective studies investigated this issue [158-163], with some reporting oncological treatment rates between $14.2 \%$ and $20 \%$ in lung cancer patients within the last 2 weeks of life $[158,163]$. While the ASCO Quality Oncology Practice Initiative has recommended the lowest possible rate of chemotherapy as one quality objective in end-of-life care [164], the problem remains unsolved regarding under which circumstances such oncological treatments are still meaningful and when they are already futile or even harmful in individual patients. However, Temel et al. [23] were able to demonstrate a lower rate of applied chemotherapies within the last 2 weeks of life (17.5\% versus $24.0 \%$ ) but yet an increased overall survival in the group of patients receiving additional early palliative care compared with the standard care group.

Standards for palliative care including hospice care have been defined on a European level by the EAPC $[165,166]$ and similarly for the USA by the National Consensus Project for Quality Palliative Care [26]. According to these definitions, the following professionals are recommended to be part of a palliative care team: palliative care physician, palliative care nurse, psychologist, social worker, physiotherapist, occupational therapist, chaplain and dietitian. While the first two are considered to build the core palliative care team, the remaining professions may join the team in liaison $[165,166]$. Palliative care services may operate on an inpatient basis (in a palliative care unit, hospital palliative care support team or 
hospice) as well as an outpatient basis (in a home palliative care team, "hospital at home", volunteer hospice team, day hospice or palliative outpatient clinic) $[165,166]$.

According to its philosophy, palliative care particularly aims at preservation of autonomy and improvement of quality of life in patients, as well as reinforcement of relationships between patients and professionals. Built upon multiprofessionality, interdisciplinarity and professional communication, its complex process can be condensed into three basic steps: repeated multidimensional assessment, team interchange, and continuous multidimensional treatment $[165,166]$.

Traditionally, the time for integrating palliative care in lung cancer was confined to the last phases of life. The WHO models of resource allocation in cancer care from 1990 [167] and 2002 [5] (the latter based on the model of the Institute for Ethics at the American Medical Association [168]) depicted an increasing need for palliative care over the course of the disease, alongside decreasing demands for disease-modifying therapies (fig. 1). In the last 5 years, a paradigmatic change has occurred that has ultimately led to the recommendation of early integration of palliative care in lung cancer patients with metastatic disease [156,

a)

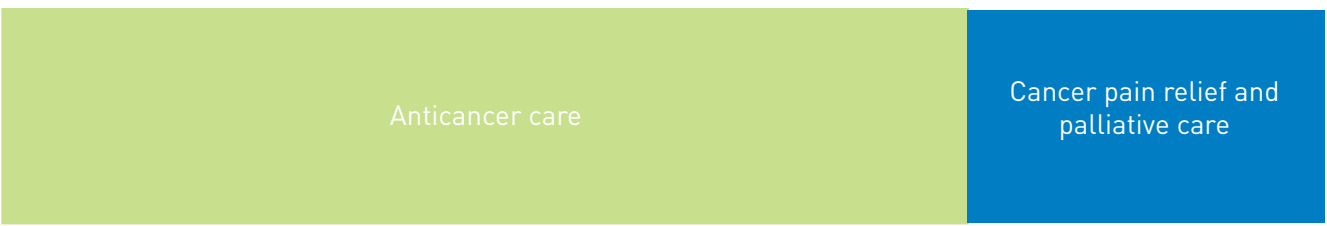

At time of

Death

diagnosis

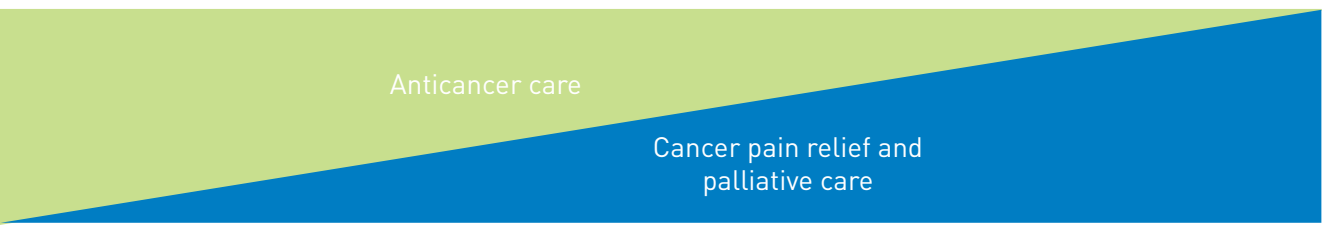

At time of

Death

diagnosis

b) Disease-modifying therapy (curative, life-prolonging or palliative in intent)

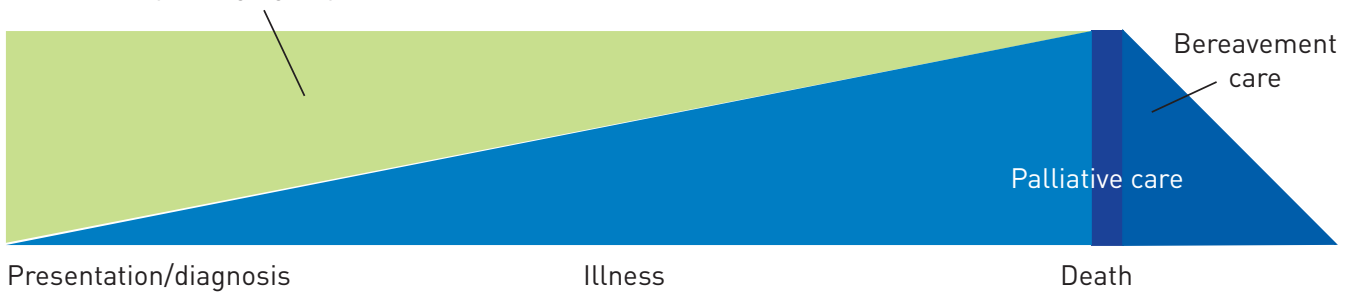

c)

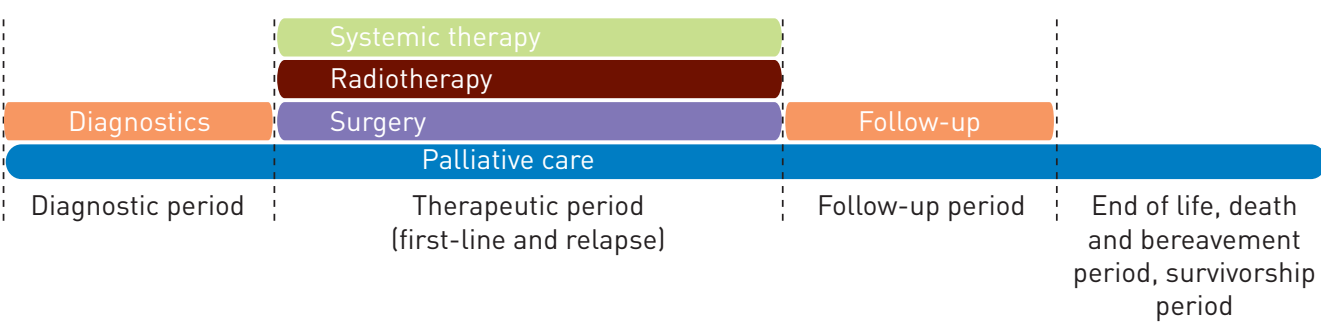

FIGURE 1 a) The World Health Organization (WHO) model of resource allocation in cancer care from 1990 depicting "present allocation of cancer resources" and "proposed allocation of cancer resources in developed countries". Reproduced from [167] with permission from the publisher. b) WHO model of "continuum of care" in association with palliative care from 2002 [5]. Source: copyright of Education for Physicians on End-of-life Care (EPEC) Project, The Robert Wood Johnson Foundation, 1999 [168]. Reproduced and modified from [168] with permission from the publisher. c) Novel integrated lung cancer care concept with diagnostics, systemic therapy, radiotherapy, surgery, palliative care and follow-up as equitable pillars of lung cancer care. 
169]. Although evidence is lacking for early stages of lung cancer, we would like to go one step further by recommending that palliative care should not only be integrated into lung cancer care from the very beginning of the disease but moreover constitute an equitable pillar of care among diagnostics, systemic therapy, radiotherapy, surgery and follow-up, instead of being regarded as separate from disease-modifying treatments. In the same manner as for the other named care modalities, palliative care should not only become an integral part of standard lung cancer care, but should be made available to lung cancer patients and their caregivers throughout the entire disease continuum as well as across diverse healthcare settings. Finally, the magnitude of its application and thus its resource allocation should be primarily depend on the extent of the patient's multidimensional needs and symptom burden, which vary individually and do not stereotypically increase with sole tumour burden or course of disease (fig. 1).

Even palliative care experts have seemed to express a certain incredulous astonishment about a previously underestimated potential of the offered interaction with the patient that has been suggested by the study of Temel et al. [23]. Fruitfully, the results raised fundamental questions on mechanisms that may generally contribute to survival time of patients with incurable lung cancer, and even throw a new light on randomised studies on tumour-specific treatment targeting the conventional items of remission and survival. Could study patients be influenced by the special attention given to them? The mechanisms of potentially lengthening survival by early palliative care are still not understood.

However, it has been concluded by other authors that the early integration of palliative care is overall beneficial for the patient $[156,170-174]$. As many patients are unable to comprehend their expectations at the time of the first diagnosis, early palliative care has definitely been shown to improve patient understanding of their outlook over time, which may have an impact on decision making about care near the end of life [128]. In summary, the evidence appears strong enough to favour an early intervention of palliative care for patients with lung cancer in all stages. In addition, clinicians seem to accept this integrated approach very well [175].

However, at a first glance, available healthcare resources seem to contradict the recommended earlier and broader integration of palliative care, since the current EAPC Atlas of Palliative Care in Europe depicted variation and shortages on the political European map [132]. Whilst increasing evidence has been published demonstrating successful implementation of palliative care or its elements into standard lung cancer care on the local level $[23,62,176-178]$, a superordinate master plan for better and encompassing delivery of palliative care in lung cancer patients is missing. For that, joint actions by governments and scientific societies are needed. Structural requirement figures for comprehensive palliative care in Europe were estimated by EAPC [166], and respiratory societies should create joint initiatives together with other stakeholders to let palliative care become a true and effective partner in routine lung cancer care.

TABLE 3 Essential steps of action for the integration of palliative care into routine lung cancer care on the local level

Planning

Information

Structure

Processes

\section{Network}

Guidance and education

Quality assurance and research
Identification of relevant stakeholders as well as existing structures and processes of lung cancer care and palliative care within own setting and local external environment

Meeting with relevant stakeholders to set up master plan for integration of palliative care into routine lung cancer care as well as establishment of cross-sectoral network

Kick-off meeting for professionals, patients, caretakers and other stakeholders Regular information measures on status of integrated lung cancer care network (i.e. newsletters, meetings)

Constitution of multiprofessional palliative care team

Set-up of inpatient and outpatient palliative care services (see main text for details on recommended professions as well as means of palliative care services)

Mandatory integration of palliative care services into existing multidisciplinary teams

Creation/implementation of workflow descriptions for palliative care processes (i.e. multidimensional assessment, multiprofessional treatment, communication)

Cross-linkage/integration of previous lung cancer care and palliative care processes within local quality management system

Set-up of network for comprehensive lung cancer care across local healthcare settings

Cooperation with other local or superordinate networks

Creation/implementation of local guidelines for lung cancer care with integrated palliative care guidance

Creation/implementation of educational measures for professionals, patients and caretakers

Creation/implementation of local quality assurance measures (i.e. audits, surveys, clinical lung cancer data registration) for continuous improvement of comprehensive lung cancer care network

Performance of studies on palliative care within own lung cancer care setting or participation in multicentre studies 
Undoubtedly, sufficient palliative care structures do need proper re-allocation of funding, but graded levels of palliative care within coordinated network structures (including trained individuals, general palliative care in hospitals or nursing services, specialist palliative care, and centres of excellence) have already been proposed as cost-saving solutions $[165,166,178,179]$, as have telephone counselling or other formats of telemedicine to overcome geographical gaps [180]. Furthermore, the Asian Oncology Summit from 2012 provided a template for a stratified allocation of palliative care according to national economic resources [181].

However, guidance and education seem to be the most influential factors for efficient integration. Lung cancer guidelines need comprehensive palliative care sections beyond sole supportive measure descriptions or, alternatively, references to overarching palliative care guidelines. Lung cancer care professionals need systematic education programmes in palliative care with a special focus on multidimensional needs assessment and communication skills, and palliative care specialists need to know about common principles of lung cancer care independent from the time of integration.

Local efforts for integration of palliative care into routine lung cancer care do not need to await national or European action plans. Instead, pneumologists should step forward to take over an active role in promoting the integration, implementation and continuous improvement of multiprofessional structures and processes within their individual local settings for lung cancer care. Palliative care should be made available and integrated by pneumologists in the diagnostic period. Table 3 highlights the essential steps of action within this local process, which may help to tailor one's own strategy depending on the particular environment.

\section{Conclusion}

As pneumologists, we are comprehensively responsible for lung cancer patients, in terms of diagnostic and therapeutic concepts and actions. Thus, we face the challenge of two major paradigmatic changes from other disciplines: the developing oncological definition of lung cancer by molecular methods, with the pertinent therapeutic concepts, and the widening horizon of an integrated, complex and active multidisciplinary care evolving from early palliative care, which is otherwise already established. This task is a promising, fruitful and spirited one, so pneumologists should act now. Furthermore, institutions for thoracic oncology should take a scientific chance from the fact that so far only sparse high-grade primary literature exists about integrated palliative care for lung cancer patients. Besides methodological deficits, previous studies were frequently retrospective and executed mainly at institutional or regional levels. This should encourage us to develop our structures and concepts together with well-designed powerful prospective evaluations, so that heart and mind come closer and closer, for the sake of our patients as well as caretakers' satisfaction.

\section{References}

Sculier JP. Nonsmall cell lung cancer. Eur Respir Rev 2013; 22: 33-36.

Schönfeld N, Blum T. Palliative care in thoracic oncology. Breathe 2012; 9: 125-131.

Gaga M, Powell CA, Schraufnagel DE, et al. An official American Thoracic Society/European Respiratory Society statement: the role of the pulmonologist in the diagnosis and management of lung cancer. Am J Respir Crit Care Med 2013; 188: 503-507.

$4 \quad$ Saunders C. St Christopher's Hospice. Brit Hosp J Soc Serv Rev 1967; 77: 2127-2130.

5 National Cancer Control Programmes. Policies and managerial guidelines. 2nd Edn. Geneva, World Health Organization, 2002. Available from: www.who.int/cancer/publications/nccp2002/en

6 Yoong J, Park ER, Greer JA, et al. Early palliative care in advanced lung cancer: a qualitative study. JAMA Intern Med 2013; 173: 283-290.

7 Alt-Epping B, Staritz AE, Simon ST, et al. What is special about patients with lung cancer and pulmonary metastases in palliative care? Results from a nationwide survey. J Palliat Med 2012; 15: 971-977.

8 Jimenez A, Madero R, Alonso A, et al. Symptom clusters in advanced cancer. J Pain Symptom Manage 2011; 42: 24-31.

9 Maric DM, Jovanovic DM, Golubicic IV, et al. Psychological well-being in advanced NSCLC patients in Serbia: impact of sociodemographic and clinical factors. Neoplasma 2010; 57: 1-7.

10 Rolke HB, Bakke PS, Gallefoss F. Health related quality of life, mood disorders and coping abilities in an unselected sample of patients with primary lung cancer. Respir Med 2008; 102: 1460-1467.

11 Sanders SL, Bantum EO, Owen JE, et al. Supportive care needs in patients with lung cancer. Psychooncology 2010; 19: 480-489.

12 Pearman T. Psychosocial factors in lung cancer: quality of life, economic impact, and survivorship implications. J Psychosoc Oncol 2008; 26: 69-80.

13 Grose D, Devereux G, Milroy R. Comorbidity in lung cancer: important but neglected. A review of the current literature. Clin Lung Cancer 2011; 12: 207-211.

14 Maguire R, Papadopoulou C, Kotronoulas G, et al. A systematic review of supportive care needs of people living with lung cancer. Eur J Oncol Nurs 2013; 17: 449-464.

15 Ugalde A, Aranda S, Krishnasamy M, et al. Unmet needs and distress in people with inoperable lung cancer at the commencement of treatment. Support Care Cancer 2012; 20: 419-423.

16 Donnelly S, Walsh D. The symptoms of advanced cancer. Semin Oncol 1995; 22: Suppl. 3, 67-72.

17 Doorenbos AZ, Given CW, Given B, et al. Symptom experience in the last year of life among individuals with cancer. J Pain Symptom Manage 2006; 32: 403-412. 
Johnsen AT, Petersen MA, Pedersen L, et al. Symptoms and problems in a nationally representative sample of advanced cancer patients. Palliat Med 2009; 23: 491-501.

Fischer DJ, Villines D, Kim YO, et al. Anxiety, depression, and pain: differences by primary cancer. Support Care Cancer 2010; 18: 801-810.

Harrison JD, Young JM, Price MA, et al. What are the unmet supportive care needs of people with cancer? A systematic review. Support Care Cancer 2009; 17: 1117-1128.

Puts MT, Papoutsis A, Springall E, et al. A systematic review of unmet needs of newly diagnosed older cancer patients undergoing active cancer treatment. Support Care Cancer 2012; 20: 1377-1394.

Miller JJ, Frost MH, Rummans TA, et al. Role of a medical social worker in improving quality of life for patients with advanced cancer with a structured multidisciplinary intervention. J Psychosoc Oncol 2007; 25: 105-119.

Temel JS, Greer JA, Muzikansky A, et al. Early palliative care for patients with metastatic non-small-cell lung cancer. N Engl J Med 2010; 363: 733-742.

Clark D. "Total pain", disciplinary power and the body in the work of Cicely Saunders, 1958-1967. Soc Sci Med 1999; 49: 727-736.

Mehta A, Chan LS. Understanding of the concept of "total pain": a prerequisite for pain control. J Hospice Palliat Nurs 2008; 10: 26-32.

Clinical Practice Guidelines for Quality Palliative Care. 3rd Edn. Pittsburgh, National Consensus Project for Quality Palliative Care, 2013. Available from: www.nationalconsensusproject.org/Guidelines_Download2.aspx

Simoff MJ, Lally B, Slade MG, et al. Symptom management in patients with lung cancer. Diagnosis and management of lung cancer, 3rd ed. American College of Chest Physicians evidence-based clinical practice guidelines. Chest 2013; 143: Suppl. 5, e455S-e497S.

Goeckenjan G, Sitter H, Thomas M, et al. Prävention, Diagnostik, Therapie und Nachsorge des Lungenkarzinoms [Prevention, diagnosis, therapy, and follow-up of lung cancer]. Pneumologie 2010; 64: Suppl. 2, e1-e164.

The Diagnosis and Treatment of Lung Cancer (Update). NICE clinical guideline. Cardiff, National Collaborating Centre for Cancer, 2011.

Heigener DF, Rabe KF. Palliative care concepts in respiratory disease. Respiration 2011; 82: 483-491.

Ripamonti CI, Santini D, Maranzano E, et al. Management of cancer pain: ESMO Clinical Practice Guidelines. Ann Oncol 2012; 23: Suppl. 7, vii139-vii154.

Kvale PA. Chronic cough due to lung tumors: ACCP evidence-based clinical practice guidelines. Chest 2006; 129: Suppl. 1, 147S-153S.

De Marinis F, Eberhardt W, Harper PG, et al. Bisphosphonate use in patients with lung cancer and bone metastases: recommendations of a European expert panel. J Thorac Oncol 2009; 4: 1280-1288.

Expert Panel On Radiation Oncology-Bone Metastases, Lutz ST, Lo SS, et al. ACR Appropriateness Criteria ${ }^{\circ}$ non-spine bone metastases. J Palliat Med 2012; 15: 521-526.

Expert Panel on Radiation Oncology-Bone Metastases, Lo SS, Lutz ST, et al. ACR Appropriateness Criteria spinal bone metastases. J Palliat Med 2013; 16: 9-19.

Kearon C, Akl EA, Comerota AJ, et al. Antithrombotic therapy for VTE disease. Antithrombotic therapy and prevention of thrombosis, 9th edn. American College of Chest Physicians Evidence-Based Clinical Practice Guidelines. Chest 2012; 141: Suppl. 2, e419S-e494S.

Lyman GH, Khorana AA, Kuderer NM, et al. Venous thromboembolism prophylaxis and treatment in patients with cancer: American Society of Clinical Oncology clinical practice guideline update. J Clin Oncol 2013; 31: 2189-2204.

Mandala M, Falanga A, Roila F, et al. Management of venous thromboembolism (VTE) in cancer patients: ESMO Clinical Practice Guidelines. Ann Oncol 2011; 22: Suppl. 6, vi85-vi92.

Farge D, Debourdeau P, Beckers $\mathrm{M}$, et al. International clinical practice guidelines for the treatment and prophylaxis of venous thromboembolism in patients with cancer. J Thromb Haemost 2013; 11: 56-70.

Verbalis JG, Goldsmith SR, Greenberg A, et al. Hyponatremia treatment guidelines 2007: expert panel recommendations. Am J Med 2007; 120: Suppl. 1, S1-S21.

Spasovski G, Vanholder R, Allolio B, et al. Clinical practice guideline on diagnosis and treatment of hyponatraemia. Eur J Endocrinol 2014; 170: G1-G47.

Roila F, Herrstedt J, Aapro M, et al. Guideline update for MASCC and ESMO in the prevention of chemotherapy- and radiotherapy-induced nausea and vomiting: results of the Perugia consensus conference. Ann Oncol 2010; 21: Suppl. 5, v232-v243.

Basch E, Prestrud AA, Hesketh PJ, et al. Antiemetics: American Society of Clinical Oncology clinical practice guideline update. J Clin Oncol 2011; 29: 4189-4198.

Rizzo JD, Brouwers M, Hurley P, et al. American Society of Clinical Oncology/American Society of Hematology clinical practice guideline update on the use of epoetin and darbepoetin in adult patients with cancer. $J$ Clin Oncol 2010; 28: 4996-5010.

Schrijvers D, De Samblanx H, Roila F, et al. Erythropoiesis-stimulating agents in the treatment of anaemia in cancer patients: ESMO Clinical Practice Guidelines for use. Ann Oncol 2010; 21: Suppl. 5, v244-v247.

Flowers CR, Seidenfeld J, Bow EJ, et al. Antimicrobial prophylaxis and outpatient management of fever and neutropenia in adults treated for malignancy: American Society of Clinical Oncology clinical practice guideline. J Clin Oncol 2013; 31: 794-810.

Smith TJ, Khatcheressian J, Lyman GH, et al. 2006 update of recommendations for the use of white blood cell growth factors: an evidence-based clinical practice guideline. J Clin Oncol 2006; 24: 3187-3205.

de Naurois J, Novitzky-Basso I, Gill MJ, et al. Management of febrile neutropenia: ESMO Clinical Practice Guidelines. Ann Oncol 2010; 21: Suppl. 5, v252-v256.

Crawford J, Caserta C, Roila F, et al. Hematopoietic growth factors: ESMO Clinical Practice Guidelines for the applications. Ann Oncol 2010; 21: Suppl. 5, v248-v251.

Schiffer CA, Anderson KC, Bennett CL, et al. Platelet transfusion for patients with cancer: clinical practice guidelines of the American Society of Clinical Oncology. J Clin Oncol 2001; 19: 1519-1538.

Yazbeck VY, Villaruz L, Haley M, et al. Management of normal tissue toxicity associated with chemoradiation (primary skin, esophagus, and lung). Cancer J 2013; 19: 231-237. 

Mucositis Secondary to Cancer Therapy. Hillerød, Multinational Association of Supportive Care in Cancer, 2014. Available from: www.mascc.org/mucositis-guidelines

53 Peterson DE, Bensadoun RJ, Roila F, et al. Management of oral and gastrointestinal mucositis: ESMO Clinical Practice Guidelines. Ann Oncol 2011; 22: Suppl. 6, vi78-vi84.

54 Ferrell B, Koczywas M, Grannis F, et al. Palliative care in lung cancer. Surg Clin North Am 2011; 91: $403-417$.

55 Zabora J, BrintzenhofeSzoc K, Curbow B, et al. The prevalence of psychological distress by cancer site. Psychooncology 2001; 10: 19-28.

56 Salvo N, Zeng L, Zhang L, et al. Frequency of reporting and predictive factors for anxiety and depression in patients with advanced cancer. Clin Oncol 2012; 24: 139-148. Ann Oncol 2013; 24: 895-900.

.

Akechi T, Okamura $\mathrm{H}$, Nishiwaki Y, et al. Psychiatric disorders and associated and predictive factors in patients with unresectable nonsmall cell lung carcinoma: a longitudinal study. Cancer 2001; 92: 2609-2622.

Akechi T, Okamura $\mathrm{H}$, Nishiwaki Y, et al. Predictive factors for suicidal ideation in patients with unresectable lung carcinoma. Cancer 2002; 95: 1085-1093.

Ginsburg ML, Quirt C, Ginsburg AD, et al. Psychiatric illness and psychosocial concerns of patients with newly diagnosed lung cancer. CMAJ 1995; 152: 701-708.

Graves KD, Arnold SM, Love CL, et al. Distress screening in a multidisciplinary lung cancer clinic: prevalence and predictors of clinically significant distress. Lung Cancer 2007; 55: 215-224.

Henoch I, Bergman B, Gustafsson M, et al. The impact of symptoms, coping capacity, and social support on quality of life experience over time in patients with lung cancer. J Pain Symptom Manage 2007; 34: 370-379.

Neron S, Correa JA, Dajczman E, et al. Screening for depressive symptoms in patients with unresectable lung cancer. Support Care Cancer 2007; 15: 1207-1212.

Shell JA, Carolan M, Zhang Y, et al. The longitudinal effects of cancer treatment on sexuality in individuals with lung cancer. Oncol Nurs Forum 2008; 35: 73-79.

Carlsen K, Jensen AB, Jacobsen E, et al. Psychosocial aspects of lung cancer. Lung Cancer 2005; 47: 293-300.

Fox SW, Lyon DE. Symptom clusters and quality of life in survivors of lung cancer. Oncol Nurs Forum 2006; 33 931-936.

Hopwood P, Stephens RJ. Depression in patients with lung cancer: prevalence and risk factors derived from quality-of-life data. J Clin Oncol 2000; 18: 893-903.

Tishelman C, Petersson LM, Degner LF, et al. Symptom prevalence, intensity, and distress in patients with inoperable lung cancer in relation to time of death. J Clin Oncol 2007; 25: 5381-5389.

Levav I. The treatment gap of depression in persons with cancer. Asian Pac J Cancer Prev 2010; 11: Suppl. 1, 117-119.

Shimizu K, Nakaya N, Saito-Nakaya K, et al. Clinical biopsychosocial risk factors for depression in lung cancer patients: a comprehensive analysis using data from the Lung Cancer Database Project. Ann Oncol 2012; 23: 1973-1979.

Cataldo JK, Brodsky JL. Lung cancer stigma, anxiety, depression and symptom severity. Oncology 2013; 85: 33-40. Carey M, Lambert S, Smits R, et al. The unfulfilled promise: a systematic review of interventions to reduce the unmet supportive care needs of cancer patients. Support Care Cancer 2012; 20: 207-219.

Lloyd-Williams M, Cobb M, O'Connor C, et al. A pilot randomised controlled trial to reduce suffering and emotional distress in patients with advanced cancer. J Affect Disord 2013; 148: 141-145.

Rueda JR, Sola I, Pascual A, et al. Non-invasive interventions for improving well-being and quality of life in patients with lung cancer. Cochrane Database Syst Rev 2011; 9: CD004282.

Walker J, Sawhney A, Hansen CH, et al. Treatment of depression in people with lung cancer: a systematic review. Lung Cancer 2013; 79: 46-53.

Delibegovic A, Sinanovic O. The influence of palliative care on the level of anxiety and depression in lung cancer patients. Med Arch 2013; 67: 263-265.

Akechi T, Okamura $\mathrm{H}$, Okuyama $\mathrm{T}$, et al. Psychosocial factors and survival after diagnosis of inoperable non-small cell lung cancer. Psychooncology 2009; 18: 23-29.

Arrieta O, Angulo LP, Nunez-Valencia C, et al. Association of depression and anxiety on quality of life, treatment adherence, and prognosis in patients with advanced non-small cell lung cancer. Ann Surg Oncol 2013; 20: 1941-1948.

Buccheri G. Depressive reactions to lung cancer are common and often followed by a poor outcome. Eur Respir J 1998; 11: 173-178.

Pirl WF, Greer JA, Traeger L, et al. Depression and survival in metastatic non-small-cell lung cancer: effects of early palliative care. J Clin Oncol 2012; 30: 1310-1315.

Faller H, Bulzebruck H. Coping and survival in lung cancer: a 10-year follow-up. Am J Psychiatry 2002; 159 : 2105-2107.

Carmack Taylor CL, Badr H, Lee JH, et al. Lung cancer patients and their spouses: psychological and relationship functioning within 1 month of treatment initiation. Ann Behav Med 2008; 36: 129-140.

Kramer BJ, Kavanaugh M, Trentham-Dietz A, et al. Complicated grief symptoms in caregivers of persons with lung cancer: the role of family conflict, intrapsychic strains, and hospice utilization. Omega 2010; 62: 201-220. Kramer BJ, Kavanaugh M, Trentham-Dietz A, et al. Predictors of family conflict at the end of life: the experience of spouses and adult children of persons with lung cancer. Gerontologist 2010; 50: 215-225.

Kim YA, Yun YH, Chang YJ, et al. Employment status and work-related difficulties in lung cancer survivors compared with the general population. Ann Surg 2014; 259: 569-575.

Chapple A, Ziebland S, McPherson A, et al. Lung cancer patients' perceptions of access to financial benefits: a qualitative study. Br J Gen Pract 2004; 54: 589-594.

Mosher CE, Champion VL, Azzoli CG, et al. Economic and social changes among distressed family caregivers of lung cancer patients. Support Care Cancer 2013; 21: 819-826. 

a cancer diagnosis on patients and their families: qualitative findings from a country with a mixed public-private healthcare system. Support Care Cancer 2013; 21: 107-117.

90 Weiss T, Weinberger M, Schwerd AM, et al. A 30-year perspective on psychosocial issues in lung cancer: how lung cancer "came out of the closet". Thorac Surg Clin 2012; 22: 449-456.

91 Salander P, Henriksson R. Severely diseased lung cancer patients narrate the importance of being included in a helping relationship. Lung Cancer 2005; 50: 155-162.

92 Williams AL, Bakitas M. Cancer family caregivers: a new direction for interventions. J Palliat Med 2012; 15: 775-783.

93 Buchanan D, Milroy R, Baker L, et al. Perceptions of anxiety in lung cancer patients and their support network. Support Care Cancer 2010; 18: 29-36.

94 Ryan LS. Lung cancer: psychosocial implications. Semin Oncol Nurs 1987; 3: 222-227.

95 Lebel S, Castonguay M, Mackness G, et al. The psychosocial impact of stigma in people with head and neck or lung cancer. Psychooncology 2013; 22: 140-152.

96 Edmonds P, Karlsen S, Khan S, et al. A comparison of the palliative care needs of patients dying from chronic respiratory diseases and lung cancer. Palliat Med 2001; 15: 287-295.

97 Hill KM, Amir Z, Muers MF, et al. Do newly diagnosed lung cancer patients feel their concerns are being met? Eur J Cancer Care 2003; 12: 35-45.

98 Li J, Girgis A. Supportive care needs: are patients with lung cancer a neglected population? Psychooncology 2006; 15: 509-516.

99 Ryan PJ, Howell V, Jones J, et al. Lung cancer, caring for the caregivers. A qualitative study of providing pro-active social support targeted to the carers of patients with lung cancer. Palliat Med 2008; 22: 233-238.

100 Richardson A, Plant H, Moore S, et al. Developing supportive care for family members of people with lung cancer: a feasibility study. Support Care Cancer 2007; 15: 1259-1269.

101 Nelson JE, Gay EB, Berman AR, et al. Patients rate physician communication about lung cancer. Cancer 2011; 117: 5212-5220.

102 Murray SA, Kendall M, Boyd K, et al. Exploring the spiritual needs of people dying of lung cancer or heart failure: a prospective qualitative interview study of patients and their carers. Palliat Med 2004; 18 : 39-45.

103 Clay KS, Talley C, Young KB. Exploring spiritual well-being among survivors of colorectal and lung cancer. J Relig Spiritual Soc Work 2010; 29: 14-32.

104 Kandasamy A, Chaturvedi SK, Desai G. Spirituality, distress, depression, anxiety, and quality of life in patients with advanced cancer. Indian J Cancer 2011; 48: 55-59.

105 Lissoni P, Messina G, Parolini D, et al. A spiritual approach in the treatment of cancer: relation between faith score and response to chemotherapy in advanced non-small cell lung cancer patients. In Vivo 2008; 22 : 577-581.

106 Improving Supportiveand Palliative Care for Adults with Cancer. The Manual. London, National Institute for Clinical Excellence, 2004. Available from: www.nice.org.uk/guidance/CSGSP

107 Davie G, Heelas P, Woodhead L, eds. Predicting Religion: Christian, Secular and Alternative Futures. Theology and Religion in Interdisciplinary Perspective Series. Aldershot, Ashgate Publishing, 2003.

108 Frick E, Riedner C, Fegg MJ, et al. A clinical interview assessing cancer patients' spiritual needs and preferences. Eur J Cancer Care 2006; 15: 238-243.

109 Williams DR, Kontos EZ, Viswanath K, et al. Integrating multiple social statuses in health disparities research: the case of lung cancer. Health Serv Res 2012; 47: 1255-1277.

110 Jonnalagadda S, Lin JJ, Nelson JE, et al. Racial and ethnic differences in beliefs about lung cancer care. Chest 2012; 142: 1251-1258.

111 Reyes-Gibby CC, Anderson KO, Shete S, et al. Early referral to supportive care specialists for symptom burden in lung cancer patients: a comparison of non-Hispanic whites, Hispanics, and non-Hispanic blacks. Cancer 2012; 118: 856-863.

112 Martin MY, Fouad MN, Oster RA, et al. What do cancer patients worry about when making decisions about treatment? Variation across racial/ethnic groups. Support Care Cancer 2014; 22: 233-244.

113 Martin MY, Sanders S, Griffin JM, et al. Racial variation in the cancer caregiving experience: a multisite study of colorectal and lung cancer caregivers. Cancer Nurs 2012; 35: 249-256.

114 Traeger L, Cannon S, Keating NL, et al. Race by sex differences in depression symptoms and psychosocial service use among non-Hispanic black and white patients with lung cancer. J Clin Oncol 2014; 32: 107-113.

115 Harding R, Epiphaniou E, Chidgey-Clark J. Needs, experiences, and preferences of sexual minorities for end-of-life care and palliative care: a systematic review. J Palliat Med 2012; 15: 602-611.

116 Reygan FC, D’Alton P. A pilot training programme for health and social care professionals providing oncological and palliative care to lesbian, gay and bisexual patients in Ireland. Psychooncology 2013; 22: 1050-1054.

117 Ford DW, Koch KA, Ray DE, et al. Palliative and end-of-life care in lung cancer. Diagnosis and management of lung cancer, 3rd ed. American College of Chest Physicians evidence-based clinical practice guidelines. Chest 2013; 143: Suppl. 5, e498S-e512S.

118 Borreani C, Miccinesi G. End of life care preferences. Curr Opin Support Palliat Care 2008; 2: 54-59.

119 Yardley SJ, Davis CL, Sheldon F. Receiving a diagnosis of lung cancer: patients' interpretations, perceptions and perspectives. Palliat Med 2001; 15: 379-386.

120 Baile WF, Buckman R, Lenzi R, et al. SPIKES - A six-step protocol for delivering bad news: application to the patient with cancer. Oncologist 2000; 5: 302-311.

121 Iyer S, Roughley A, Rider A, et al. The symptom burden of non-small cell lung cancer in the USA: a real-world cross-sectional study. Support Care Cancer 2014; 22: 181-187.

122 Siminoff LA, Dorflinger L, Agyemang A, et al. Oncologists' assessments of lung cancer patient and family disagreements regarding treatment decision making. Lung Cancer 2012; 77: 212-216.

123 Uchitomi Y, Mikami I, Nagai K, et al. Depression and psychological distress in patients during the year after curative resection of non-small-cell lung cancer. J Clin Oncol 2003; 21: 69-77.

124 Gabrijel S, Grize L, Helfenstein E, et al. Receiving the diagnosis of lung cancer: patient recall of information and satisfaction with physician communication. J Clin Oncol 2008; 26: 297-302. 
Nehls W, Gabrijel S, Kiss A, et al. Physician communication in a lung cancer center - does the message come across? Pneumologie 2013; 67: 688-693.

World Medical Association International Code of Medical Ethics. http://web.archive.org/web/20080920142540/ http://www.wma.net/e/policy/c8.htm Date last accessed: April 6, 2014. Date last updated: October 14, 2006.

Peppercorn JM, Smith TJ, Helft PR, et al. American society of clinical oncology statement: toward individualized care for patients with advanced cancer. J Clin Oncol 2011; 29: 755-760.

Temel JS, Greer JA, Admane S, et al. Longitudinal perceptions of prognosis and goals of therapy in patients with metastatic non-small-cell lung cancer: results of a randomized study of early palliative care. J Clin Oncol 2011; 29: 2319-2326.

Schönfeld N, Timsit JF. Overcoming a stigma: the lung cancer patient in the intensive care unit. Eur Respir J 2008; 31: 3-5.

Hyodo I, Eguchi K, Takigawa N, et al. Psychological impact of informed consent in hospitalized cancer patients. A sequential study of anxiety and depression using the hospital anxiety and depression scale. Support Care Cancer 1999; 7: 396-399.

Blum TG, Rich A, Baldwin D, et al. The European initiative for quality management in lung cancer care. Eur Respir J 2014; 43: 1254-1277.

Centeno C, Lynch T, Donea O, et al. EAPC Atlas of Palliative Care in Europe 2013. Full Edn. Milan, European Association for Palliative Care, 2013. Available from: www.eapcnet.eu/Themes/Organisation/ DevelopmentinEurope/EAPCAtlas2013.aspx

Hardy D, Chan W, Liu CC, et al. Racial disparities in the use of hospice services according to geographic residence and socioeconomic status in an elderly cohort with nonsmall cell lung cancer. Cancer 2011; 117: 1506-1515.

Lamba S, Nagurka R, Zielinski A, et al. Palliative care provision in the emergency department: barriers reported by emergency physicians. J Palliat Med 2013; 16: 143-147.

Steele R, Fitch MI. Why patients with lung cancer do not want help with some needs. Support Care Cancer 2008; 16: 251-259.

Mosher CE, Champion VL, Hanna N, et al. Support service use and interest in support services among distressed family caregivers of lung cancer patients. Psychooncology 2013; 22: 1549-1556.

Beernaert K, Deliens L, De Vleminck A, et al. Early identification of palliative care needs by family physicians: a qualitative study of barriers and facilitators from the perspective of family physicians, community nurses, and patients. Palliat Med 2014; 28: 480-490.

Ward AM, Agar M, Koczwara B. Collaborating or co-existing: a survey of attitudes of medical oncologists toward specialist palliative care. Palliat Med 2009; 23: 698-707.

Abrahm JL. Integrating palliative care into comprehensive cancer care. J Natl Compr Canc Netw 2012; 10: 1192-1198.

Koczywas M, Cristea M, Thomas J, et al. Interdisciplinary palliative care intervention in metastatic non-small-cell lung cancer. Clin Lung Cancer 2013; 14: 736-744.

Koczywas M, Williams AC, Cristea M, et al. Longitudinal changes in function, symptom burden, and quality of life in patients with early-stage lung cancer. Ann Surg Oncol 2013; 20: 1788-1797.

Wintner LM, Giesinger JM, Zabernigg A, et al. Quality of life during chemotherapy in lung cancer patients: results across different treatment lines. Br J Cancer 2013; 109: 2301-2308.

Claassens L, van Meerbeeck J, Coens C, et al. Health-related quality of life in non-small-cell lung cancer: an update of a systematic review on methodologic issues in randomized controlled trials. J Clin Oncol 2011; 29: 2104-2120.

Movsas B, Moughan J, Sarna L, et al. Quality of life supersedes the classic prognosticators for long-term survival in locally advanced non-small-cell lung cancer: an analysis of RTOG 9801. J Clin Oncol 2009; 27: 5816-5822.

Montazeri A, Gillis CR, McEwen J. Quality of life in patients with lung cancer: a review of literature from 1970 to 1995 . Chest $1998 ; 113: 467-481$.

Montazeri A, Milroy R, Hole D, et al. Quality of life in lung cancer patients: as an important prognostic factor. Lung Cancer 2001; 31: 233-240.

Ouwens M, Hermens R, Hulscher M, et al. Development of indicators for patient-centred cancer care. Support Care Cancer 2010; 18: 121-130.

Sarna L, Riedinger MS. Assessment of quality of life and symptom improvement in lung cancer clinical trials. Semin Oncol 2004; 31: Suppl. 9, 1-10.

Eccles M, Grimshaw J, Campbell M, et al. Research designs for studies evaluating the effectiveness of change and improvement strategies. Qual Saf Health Care 2003; 12: 47-52.

Campbell M, Fitzpatrick R, Haines A, et al. Framework for design and evaluation of complex interventions to improve health. BMJ 2000; 321: 694-696.

Schofield P, Ugalde A, Carey M, et al. Lung cancer: challenges and solutions for supportive care intervention research. Palliat Support Care 2008; 6: 281-287.

2 Bausewein C, Daveson B, Benalia H, et al. Outcome Measurement in Palliative Care. The Essentials. PRISMA project (Reflecting the Positive Diversities of European Priorities for Research and Measurement in End-of-Life Care), 2011. Available from: www.eapcnet.eu/Themes/Clinicalcare/Outcomemeasurement/Publicationsdocuments/ tabid/1577/ctl/Details/ArticleID/277/mid/2998/Outcome-Measurement-in-Palliative-Care-The-Essentials.aspx

Harding R, Higginson IJPRISMAPRISMA: a pan-European co-ordinating action to advance the science in end-of-life cancer care. Eur J Cancer 2010; 46: 1493-1501.

Lodato JE, Aziz N, Bennett RE, et al. Achieving palliative care research efficiency through defining and benchmarking performance metrics. Curr Opin Support Palliat Care 2012; 6: 533-542.

55 BTS recommendations to respiratory physicians for organising the care of patients with lung cancer. The Lung Cancer Working Party of the British Thoracic Society Standards of Care Committee. Thorax 1998; 53: Suppl. 1, $\mathrm{S} 1-\mathrm{S} 8$.

56 Smith TJ, Temin S, Alesi ER, et al. American Society of Clinical Oncology provisional clinical opinion: the integration of palliative care into standard oncology care. J Clin Oncol 2012; 30: 880-887.

57 Powell HA, Baldwin DR. Multidisciplinary team management in thoracic oncology: more than just a concept? Eur Respir J 2014; 43: 1776-1786. 
Murillo JR Jr, Koeller J. Chemotherapy given near the end of life by community oncologists for advanced non-small cell lung cancer. Oncologist 2006; 11: 1095-1099.

Reinmuth N, Payer N, Muley T, et al. Treatment and outcome of patients with metastatic NSCLC: a retrospective institution analysis of 493 patients. Respir Res 2013; 14: 139.

Adam H, Hug S, Bosshard G. Chemotherapy near the end of life: a retrospective single-centre analysis of patients' charts. BMC Palliat Care 2014; 13: 26.

Nieder C, Tollali T, Dalhaug A, et al. Active anticancer treatment during the final month of life in patients with non-small cell lung cancer. Anticancer Res 2014; 34: 1015-1020.

Kypriotakis G, Francis LE, O'Toole E, et al. Preferences for aggressive care in underserved populations with advanced-stage lung cancer: looking beyond race and resuscitation. Support Care Cancer 2014; 22: 1251-1259.

Numico G, Trogu A, Cristofano A, et al. Active treatment given in the last weeks of life: poor quality cancer care or justifiable behavior? Support Care Cancer 2014; 22: 2813-2819.

American Society of Clinical Oncology. Summary of Current Quality Oncology Practice Initiative (QOPI) Measures. 2013. Available from: www.asco.org/institute-quality/summary-current-qopi-measures $\# 8$ Radbruch L, Payne S. White Paper
Eur J Palliat Care 2009; 16: 278-289.

Radbruch L, Payne S. White Paper on standards and norms for hospice and palliative care in Europe: part 2. Eur J Palliat Care 2010; 17: 22-33.

Cer pain relief and palliative care. Report of a WHO Expert Committee. WHO Technical Report Series, No. 804. Geneva, World Health Organization, 1990. http://whqlibdoc.who.int/trs/WHO_TRS_804.pdf

Education for Physicianson End-of-life Care (EPEC). Plenary 3: Elements and Models of End-of-life Care. Participant's Handbook. EPEC Project, The Robert Wood Johnson Foundation. Chicago, American Medical Association, 1999. www.ama-assn.org/ethic/epec/download/plenary_3.pdf

Shin J, Temel J. Integrating palliative care: when and how? Curr Opin Pulm Med 2013; 19: 344-349.

Otsuka M, Koyama A, Matsuoka $\mathrm{H}$, et al. Early palliative intervention for patients with advanced cancer. Jpn J Clin Oncol 2013; 43: 788-794.

Zimmermann C, Swami N, Krzyzanowska M, et al. Early palliative care for patients with advanced cancer: a cluster-randomised controlled trial. Lancet 2014; 383: 1721-1730.

Bakitas M, Lyons KD, Hegel MT, et al. Effects of a palliative care intervention on clinical outcomes in patients with advanced cancer: the Project ENABLE II randomized controlled trial. JAMA 2009; 302: 741-749.

Gade G, Venohr I, Conner D, et al. Impact of an inpatient palliative care team: a randomized control trial. J Palliat Med 2008; 11: 180-190.

Brumley R, Enguidanos S, Jamison P, et al. Increased satisfaction with care and lower costs: results of a randomized trial of in-home palliative care. J Am Geriatr Soc 2007; 55: 993-1000.

Le BH, Mileshkin L, Doan K, et al. Acceptability of early integration of palliative care in patients with incurable lung cancer. J Palliat Med 2014; 17: 553-558. cancer therapy: a feasibility project. J Palliat Med 2010; 13: 727-732.

Jacobsen J, Jackson V, Dahlin C, et al. Components of early outpatient palliative care consultation in patients with metastatic nonsmall cell lung cancer. J Palliat Med 2011; 14: 459-464.

Bruera E, Hui D. Conceptual models for integrating palliative care at cancer centers. J Palliat Med 2012; 15: 1261-1269.

Smith TJ, Coyne PJ, Cassel JB. Practical guidelines for developing new palliative care services: resource management. Ann Oncol 2012; 23: Suppl. 3, 70-75.

Downe-Wamboldt BL, Butler LJ, Melanson PM, et al. The effects and expense of augmenting usual cancer clinic care with telephone problem-solving counseling. Cancer Nurs 2007; 30: 441-453.

Payne S, Chan N, Davies A, et al. Supportive, palliative, and end-of-life care for patients with cancer in Asia: resource-stratified guidelines from the Asian Oncology Summit 2012. Lancet Oncol 2012; 13: e492-e500. 